W stużbie tradycji i odnowy liturgicznej. 50 lat Instytutu Liturgicznego w Krakowie (1968-2018), red. P. Nowakowski, J. Mieczkowski, Kraków 2019, s. 71-79.

ISBN 978-83-7438-849-8 (wersja drukowana), ISBN 978-83-7438-850-4 (wersja online) DOI:http://dx.doi.org/10.15633/9788374388504.07

Jarosław Superson SAC

Uniwersytet Papieski Jana Pawea II w Krakowie, Polska

ORCID: 0000-0003-3770-184X

\title{
Myśl teologiczna krakowskiego Instytutu Liturgicznego w posoborowym pięćdziesięcioleciu (2)
}

W niniejszej prezentacji chciałbym przedstawić dwa szczegółowe zagadnienia, z którymi zmierzono się, prowadząc badania w Katedrze Teologii Liturgii. Owoce tych badań zostały już przedstawione w publikacjach. Zagadnienia te reprezentują nurt źródłowy badań nad liturgią obecny w działalności naukowej Katedry Teologii Liturgii, który ukazała wyżej s. dr hab. Adelajda Sielepin, prof. UPJPII. Stawia on sobie za cel poznanie i przybliżenie tradycji uzasadniającej współczesną formę i euchologię liturgicznej celebracji.

\section{Preces godzin kanonicznych}

W Rzymie w 1986 roku Natanaele Fantini przedstawił wykład zatytułowany Stosowanie Biblii w liturgii. Liturgia godzin. Chociaż mówił w nim o psalmach, to odnotował ich obecność jedynie w psalmodii. Wykład ten odbył się podczas XV Tygodnia Studyjnego Stowarzyszenia Profesorów 
Liturgii pod tytułem Biblia w liturgii ${ }^{1}$. W studium nad euchologia, jak uczy prof. Renato De Zan z Papieskiego Instytutu Liturgicznego w Rzymie, badanie źródeł ma znaczenie zasadnicze. Ten włoski badacz stwierdza na kartach podręcznika Scientia liturgica, że uwidocznienie w euchologii cytacji czy aluzji biblijnych to wykazanie jej źródeł pierwszorzędnych². Do dziś brakuje studium, które wskazywałoby pełny zestaw źródeł współczesnych preces umieszczonych $\mathrm{w}$ liturgia horarum, a przecież współczesny system preces, cykliczny i zmienny, jak podaje Vincenzo Raffa, przewiduje rotację około 2 tys. formuł w ciągu roku³. Ta część depozytu lex orandi nie została należycie dostrzeżona przez badaczy reprezentujących nauki liturgiczne.

Owocem pracy w Katedrze Teologii Liturgii jest monografia pod tytułem Wersety psalmiczne $w$ preces godzin kanonicznych. Studium historyczno-liturgiczne ${ }^{4}$, która zmierzyła się z zadaniem wskazania obecności źródła biblijnego - wersetu psalmicznego - w preces godzin kanonicznych. Monografia, przygotowana przede wszystkim przy zastosowaniu metody historyczno-genetycznej, pokazała obecność komponentu preces na przestrzeni wieków, od pierwszych świadectw realizujących zadanie zostawione przez Apostoła Narodów w I Tm 2, 1-4 aż do obecnie obowiązującej formy preces zawartej w liturgia horarum.

W monografii zaprezentowano polskiemu czytelnikowi szereg liturgicznych źródeł incydentalnie pojawiających się w polskich dysertacjach, dzięki którym może on dostrzec obecność wersetu psalmicznego w preces. Do najważniejszych z nich należą: Antyfonarz z Bangor; Liber officialis Amalarego z Metzu; tekst zwany Orationes maiores sive Preces ad Laudes matutinas

1 Por. N. Fantini, L'uso della Bibbia nella liturgia: Liturgia delle Ore, w: La Bibbia nella liturgia. Atti della XV Settimana di Studio dell'Associazione Professori di Liturgia. Sassone Frattocchie (Roma): 18-22 agosto 1986, a cura di Associazzione Professori di Liturgia, Genova 1987, s. 57-81 (Studi di Liturgia - Nuova serie, 15).

2 Por. R. L. De Zan, Interpretazione delle fonti, w: Scientia liturgica. Manuale di Liturgia, a cura di A. J. Chupungco, vol. 1, Introduzione alla liturgia, Casale Monferrato 1998, s. 383.

3 Por. V. Raffa, Le intercessioni di Lodi e Vespri, „Ephemerides Liturgicae” [dalej: EL] LXXXVI (1972), s. 41.

4 Por. J. Superson, Wersety psalmiczne w preces godzin kanonicznych. Studium historyczno-liturgiczne, red. M. T. Gronowski, J. Superson, Kraków 2015 (Modlitwa Kościoła. Monografie, 2). 
et ad Vesperas dicendae z IX wieku; Manuale ambrosianum z Valtravalia; Liber horarum z Silos z XI wieku; Ordo Officiorum Ecclesiae Lateranensis z XII wieku; Ordinarium papieża Innocentego III; Brewiarz Kanonika Johannesa Arwilrego (Ahrweilera) z 1260 roku; Breviarium Gothicum secundum regulam beatissimi Isidori; Breviarium romanum ex sacra potissimum Scriptura et probatis sanctorum historiis collectum et concinnatum (Breviarum sanctae Crucis); Breviarium Colbertinum i Breviarium Romanum z 1568 roku i 1961 roku. Dodatkowo skorzystano ze studium historycznego autorstwa Angela Lameriego pod tytułem La "Pontificia Commissio de sacra liturgia praeparatoria Concilii Vaticani II". Documenti, testi, verbali, opartego na źródłach przechowywanych w Tajnym Archiwum Watykańskim, dotyczących tworzenia się schematu przyszłej konstytucji o liturgii, oraz na dokumentacji grup studyjnych Coetus IX i Coetus XII bis, odpowiedzialnych za przygotowanie nowej księgi do liturgii godzin kanonicznych.

Przywołując niektóre rezultaty badań odnotowane już we wspomnianej monografii, należy podkreślić:

1. Preces formułowane przez wyznawców Jezusa Chrystusa od samego początku podczas godzin kanonicznych nigdy nie zostały zredagowane w sposób ostateczny i stały. Rodzaj preces opracowany w danej epoce Kościoła wyrażał ówczesną świadomość wiary. Pomimo wysiłków badaczy trudno wykazać, dlaczego werset psalmiczny, często powtarzający się w prośbach, miał realizować Pawłowy zapis z 1 Tm 2, 1-4.

2. Preces, które zredagowano na potrzeby liturgii nie bazyliki na Lateranie, ale dworu papieża Innocentego III, zostały przez zakon franciszkański rozpowszechnione w świecie, a następnie wykorzystane przez opracowujących preces brewiarza potrydenckiego jako ich podstawa. Preces oddane w tym brewiarzu są przede wszystkim rodzajem centonu psalmicznego zbudowanego z wersetów psalmów o charakterze lamentacji. W centonie tym jest także wezwanie „Wieczny odpoczynek daj im, Panie”, które zostało utworzone na podstawie tekstu z apokryficznej Czwartej Księgi Ezdrasza. Warto tylko przypomnieć, że po raz pierwszy liturgiczną formułę „Wieczny odpoczynek daj im, Panie” odnotowano w preces zwanych Orationes maiores sive Preces ad Laudes z IX wieku'5.

5 Por. S. Bäumer, Historie du Bréviare, traduct. R. Biron, vol. 2, Paris 1905, s. 441; P. Alfonso, Verso le origini delle Preci dell'Ufficio, „Rivista Liturgica” [dalej: RiL] XII (1925), s. 218. 
3. W 1961 roku pojawia się nowy brewiarz. Publikacja tej księgi wpisuje się w czas propagowania liturgicznej odnowy i nowej organizacji rubryk, ale jak zauważa profesor Pietro Sorci, odnowa ta nie miała inspiracji teologicznej i duszpasterskiej ${ }^{6}$. Preces, oddane $\mathrm{w}$ tym brewiarzu $\mathrm{w}$ formie wersetów psalmicznych, mają charakter pokutny, są zanoszone na klęcząco i przypisane do laudesów i nieszporów niektórych dni tygodnia w wybranych momentach roku liturgicznego. Ten stan redukcji preces $\mathrm{w}$ brewiarzu z 1961 roku jest raczej wyrazem propagowania minimalizmu niż odnowy. Już kilka lat później, w 1965 roku, Balthasar Fischer (zm. 2001), mówiąc o tych preces, nazwał je elementem zamrożonym, elementem w stanie dekadencji .

4. Po zakończonej VIII sesji Consilium w kwietniu 1967 roku została powołana grupa studyjna - Coetus a studiis XII bis - odpowiedzialna za przygotowanie nowych preces dla posoborowej liturgii godzin. Podjęła ona decyzję, że nowe prośby będą musiały odznaczać się zwięzłościa, być dostosowane do recytacji indywidualnej i zbiorowej i mieć charakter szczegółowy. Zdecydowano, że preces laudesów i nieszporów będą zredagowane bądź to ex capitellis psalmicis (genus ", $\mathrm{A}^{\prime)}$, bądź ex collectis (genus „B" $)^{8}$. Członkowie grupy nie opowiedzieli się za kopiowaniem z Księgi Psalmów poszczególnych wersetów i włączaniem ich w tej postaci do preces invocationes czy intercessiones posoborowego oficjum. Niemniej jednak kwerenda przyniosła jednoznaczne dowody na to, że wersety psalmiczne były źródłem wielu preces zapisanych w liturgia horarum. Najczęściej pobierano jakieś wyrażenie lub jakiś zwrot z wersetu lub wersetów psalmicznych, aby następnie umieścić je $\mathrm{w}$ formule, lub na podstawie wersetu psalmicznego czy kilku wersetów komponowano nowy zapis tekstualny próśb. Znając

6 Por. P. Sorci, L'ultima „editio typica” dei libri tridentuni: 1961-1962, RiL XCXIX (2012), s. 875 .

7 Por. Consilium ad exsequendam Constitutionem de Sacra Liturgia, Coetus a studiis IX, "De structura generali Officii Divini". Acta de Officio Divino in adunatione commissionis coordinatricis et in sessione VIII Consilii mensis aprilis 1967, Schemata n. 227, De Breviario 48, z dnia 8 maja 1967, S. 12.

8 Por. Consilium ad exsequendam Constitutionem de Sacra Liturgia, Coetus XII bis, „De precibus in Laudibus et in Vesperis", Schemata n. 243, De Breviario 58, z dnia 18 września 1967, S. 12. 
źródła preces, w tym przypadku wersety psalmiczne, można dokładniej określić zawartą w nich lex credendi niż z samej tylko ich lektury.

5. Taka praktyka komponowania preces wskazuje na wpływ Biblii, to jest Księgi Psalmów, na liturgię. W takiej praktyce ujawnia się sensus Ecclesiae: jako twórczość modlącego się Kościoła i jego świadomość, za kogo należy się modlić. Preces zbudowane na podstawie wersetów psalmicznych są gotową odpowiedzią na słowo Boże. Dynamizm słowa Bożego zawarty w preces jest uwłaszczony i aktualizowany, a więc ciągle żywe słowo Boże sprawia, że "Scriptura crescit cum orante" i "Scriptura crescit cum Ecclesia orante".

6. Norma 188 Ogólnego wprowadzenia do "Liturgii godzin" daje możliwość dodania do zatwierdzonych już preces nowych próśb wynikających z jakichś „szczególnych okoliczności". Realizując tę normę, modlący się Kościół nie tylko wyraża swoje liczne potrzeby, ale i pobudza do tworzenia środowiska kontynuacji redakcji preces.

\section{Ołtarz, krzyż i kierunek zanoszonych modlitw}

Drugie szczegółowe zagadnienie, z którym zmierzono się, prowadząc badania w Katedrze Teologii Liturgii, dotyczy ołtarza, krzyża i kierunku zanoszenia modlitw.

W 2000 roku kardynał Joseph Ratzinger opublikował książkę pod tytułem Duch liturgii, której treści dotyczą między innymi ołtarza, krzyża na nim i kierunku zanoszonych modlitw. Treści zaprezentowane przez kardynała w publikacji i jego polemika z prof. Pierre'em-Marie Gy na łamach „La Maison Dieu" wywołały szeroką dyskusję wśród teologów, a zwłaszcza liturgistów. Pojawiła się publikacja Orientation in Liturgical Prayer Uwego Michaela Langa, a ponadto sam Benedykt XVI, widząc dyskusje i recenzje dotyczące jednego z rozdziałów Ducha liturgii, zatytułowanego Ołtarz i kierunek modlitwy liturgicznej, podczas przygotowywania tomu 11 swoich Opera omnia pod tytułem Teologia liturgii nosił się z zamiarem usunięcia tego rozdziału`. Opracowując zagadnienie kierunku modlitwy liturgicznej, Jo-

9 Por. Benedykt XVI, Przedmowa do wprowadzajacego tomu moich pism, w: J. Ratzinger, Teologia liturgii. Sakramentalne podstawy życia chrześcijańskiego, tłum. W. Szymona, Lublin 2012, s. 2-3 (Opera omnia, 11). 
seph Ratzinger korzystał z rezultatów badań Erika Petersona. Warto w tym miejscu przypomnieć, że owoce badań Petersona były tematem międzynarodowego sympozjum poświęconego temu badaczowi, które odbyło się w październiku 2012 roku w Rzymie. Wygłoszone referaty opublikowała Pontificia Academia Theologica. Temat orientacji zanoszonych modlitw był zaprezentowany podczas sympozjum przez Gerarda Rouwhorsta ${ }^{10}$.

Przywołując niektóre rezultaty badań odnotowane w publikacji Ołtarz, krzyż i kierunek zanoszonych modlitw ${ }^{11}$, należy podkreślić:

1. Chrześcijański znak krzyża jest rozumiany jako wyraz miłości Jezusa Chrystusa do człowieka, a bez tego znaku miłość ta nie zostałaby poznana. Znak krzyża stał się wyrazem świadectwa o Zmartwychwstałym.

2. Pierwsze wspólnoty gromadzące się na łamanie chleba nie wznosiły ołtarzy, ale z czasem, gdy chrześcijanie wkroczyli do bazyliki, jeden ołtarz, wzniesiony na potrzeby liturgii, staje się biegunem, ku któremu wszyscy się zwracają.

3. Pojawienie się zwyczaju zanoszenia modlitw ku wschodowi jest wszystkim znane. Korzenie tego zwyczaju są antyczne, ale nie potrafimy ustalić przyczyn tego zjawiska ${ }^{12}$. Zagadnienie to wiąże się z budowaniem kościołów na linii wschód-zachód, ale nie zawsze przestrzegano tej praktyki jako jedynie obowiązującej.

4. U św. Augustyna wiele kazań kończyło się modlitwą zachęcającą do zwrócenia się ku wschodowi: „Conversi ad Dominum”³. Jak zauważa Paul De Clerck,

10 Por. G. Rouwhorst, Elementi ebraici nella liturgia della Chiesa delle origini in Erik Peterson, w: Erik Peterson. La presenza teologica di un outsider, a cura di G. Caronello, Città del Vaticano 2012, s. 456, 459-460 (Pontificia Academia Theologica, Itineraria, 7).

11 Por. J. Superson, Ottarz, krzyż i kierunek zanoszonych modlitw, Kraków 2014.

12 Por. M. Wallraff, La preghiera verso oriente alle origini di un uso liturgico, w: La preghiera nel tardo antico. Dalle origini ad Agostino. XXVII Incontro di studiosi dell'antichità cristiana. Roma, 7-9 maggio 1998, Roma 1999, s. 464 (Studia Ephemeridis Augustianum, 66).

13 Por. U. M. Lang, Rivolti al Signore. L'orientamento nella preghiera liturgica, prefazione J. Ratzinger, trad. L. Tasso, Siena 2006, s. 38; Sanctus Aurelius Augustinus Episcopus Hipponensis, Operum, pars 3, Opera exegetica. Enarrationes in psalmos. Speculum. De consensu Evangelistarum Lib. IV, Parisiis 1837, s. 90 (Collectio selecta SS. Ecclesiae Patrum complectens exquisitissima opera tum dogmatica et moralia, tum apologetica et oratoria, 120); L. De Coninck i in., Le „Sermo 
nie zawsze wiemy, jaką funkcję spełniały te słowa, ale ich sens jest jasny: modlitwa polega na zwróceniu się sercem do Boga, niezależnie od tego, czy łączy się z nią skierowane ku Niemu ludzkie ciało. Jeśli kiedyś chrześcijanie zajmowali tę postawę na czas modlitwy, była ona jedynie jej uzewnętrznieniem ${ }^{14}$.

5. Zasada zanoszenia modlitw ku wschodowi została złamana już z chwilą stawiania ołtarzy bocznych. Znikła wówczas także reguła: jedna ofiara, jeden ołtarz, jedno zgromadzenie. Przyczyniło się to do fragmentaryzacji liturgii sprawowanej w konkretnym miejscu.

6. Podczas obrzędu obmycia krzyża, który był sprawowany w bazylice w Jerozolimie, między innymi w święto Podwyższenia Krzyża (14 września), stawiano krzyż na ołtarzu ${ }^{15}$. Od VI wieku krzyż, ku któremu kieruje się modlitwy, jest stawiany na ołtarzach w nestoriańskich opactwach. Modlitwy te równocześnie są zanoszone ku wschodowi, ale zwyczaj ten nie przyjął się na Zachodzie ${ }^{16}$. W XI wieku ma miejsce samodzielna inicjatywa prezbiterów na Zachodzie, którzy na czas sprawowania przez siebie mszy świętej stawiają krzyż na ołtarzu. Ma to miejsce przy tych ołtarzach, jak zaznacza Joseph Lechner z Katolickiego Uniwersytetu w Eichstätt, gdzie sprawujący Przenajświętszą Ofiarę jest odwrócony plecami do zgromadzenia.

7. W Watykanie papież Sykstus IV (1471-1484) pozwolił, aby w kaplicy Sykstyńskiej ołtarz dosunięto do ściany zachodniej i w ten sposób sam pontifex sprawował Eucharystię ku zachodowi. Dwór papieski obecny na papieskiej liturgii widział jego plecy ${ }^{17}$. Jest to pierwsze świadectwo mówiące o takiej postawie papieża podczas celebracji Eucharystii.

ad populum" LXVII de saint Augustin. Introduction, édition, annotations critiques, "Augustiniana” CIV (2004), s. 33.

14 P. De Clerck, Zrozumieć liturgię, tłum. S. Czerwik, Kielce 1997, s. 162 (Vetera et Nova, 5).

15 Por. R. Salvarini, Il Santo Sepolcro a Gerusalemme. Riti, testi e racconti tra Costantino e l'età delle crociate, Città del Vaticano 2012, s. 103-104 (Monumenta Studia Instrumenta Liturgica, 68). 16 Por. E. Peterson, La croce e la preghiera verso oriente, EL LIX (1945), s. 56-57; M. Righetti, Manuale di storia liturgica, vol. 1, Introduzione generale, Milano 1955², s. 446 .

17 Por. S. de Blaauw, Innovazioni nello spazio di culto fra basso medioevo e cinquecento. La perdita dell'orientamento liturgico e la liberazione della navata, w: Lo spazio e il culto. Relazioni tra edificio ecclesiale e uso liturgico dal XV al XVI secolo, a cura di J. Stabenow, Venezia 2006, s. 35. 
8. Jednym z owoców przywoływanej publikacji jest polski tekst bulli papieża Benedykta XIV O wizerunku ukrzyżowanego Zbawiciela na krzyżu wystawionym na ottarzach z 1746 roku. Z bulli wynika jednoznacznie, że Benedykt XIV przeciwstawił się tym wszystkim, którzy nie umieszczali na ołtarzu krzyża podczas celebracji czy też zastępowali go wizerunkiem świętego.

9. Dokumenty po Soborze Watykańskim II postulują umieszczenie ołtarza z dala od ściany, aby go łatwo można było obejść i aby celebra mogła się odbywać twarzą do ludu. Ma on stanowić ośrodek, na którym samorzutnie skupia się uwaga całego zgromadzenia wiernych. Natomiast krzyż, zaliczany do zdobień ołtarza, może być ustawiony na ołtarzu lub obok niego. Podczas celebracji można skorzystać z krzyża procesyjnego, stawianego przed ołtarzem, krzyża zawieszonego w apsydzie bądź krzyża zwisającego z wysoka. Dokumenty posoborowe nie charakteryzują krzyża jako znaku, ku któremu są zanoszone modlitwy prezbitera i zgromadzonego ludu Bożego. Nie mówią także o geograficznym wschodzie jako kierunku zanoszenia modlitw. Sformułowanie „celebracja zwrócona ku ludowi” nie ma sensu teologicznego, ale topograficzno-pozycjonalny. Każda celebracja Eucharystii jest „,ad laudem et gloriam nominis Dei, ad utilitatem quoque nostram, totiusque Ecclesiae suae sanctae". Teologicznie zatem msza jest zawsze zwrócona ku Bogu i ku ludowi. W formie celebrowania należy być uważnym, aby nie zamienić teologii i topografii, przede wszystkim wówczas, kiedy kapłan jest przy ołtarzu. Tylko podczas dialogów od ołtarza kapłan mówi do ludu. Cała reszta jest modlitwą do Ojca poprzez Chrystusa w Duchu Świętym. Ta teologia musi być widoczna ${ }^{18}$.

\section{Riassunto}

\section{Il pensiero teologico dell'Istituto Liturgico di Cracovia nel cinquante- nario post conciliare (2)}

1. A Roma nel 1986 Natanaele Fantini ha tenuto una conferenza intitolata $L^{\prime} u s o$ della Bibbia nella liturgia. Liturgia delle Ore. Anche se parlava dei salmi, ha notato la loro presenza soltanto nella salmodia. La conferenza si è svolta durante la XV

18 Pregare "ad orientem versus”, „Notitiae” 29 (1993) num. 5, s. 249. 
Settimana di Studio dell'Associazione Professori di Liturgia dal titolo La Bibbia nella liturgia. Nello studio sull'eucologia, come insegna prof. Renato De Zan del Pontificio Istituto Liturgico di Roma, l'esame delle fonti ha un'importanza fondamentale. Questo ricercatore italiano conferma sulle pagine del manuale Scientia liturgica che rendere evidenti nell'eucologia le citazioni o allusioni bibliche, significa rivelare le sue fonti primarie. Fino ad oggi manca uno studio che indicherebbe un pieno repertorio di fonti contemporanee di preces inserite in Liturgia horarum, mentre il sistema contemporaneo di preces, ciclico e mutevole, come riferisce Vincenzo Raffa, prevede una rotazione di circa 2 mila formule durante l'anno. Questa parte del deposito lex orandi non è stata debitamente intravista dagli scienziati che rappresentano le scienze liturgiche.

Un frutto del lavoro intrapreso nella Cattedra di Teologia della Liturgia è la monografia intitolata Wersety psalmiczne w preces godzin kanonicznych. Studium historyczno-liturgiczne, che ha affrontato il compito di indicare la presenza della fonte biblica - versetto salmico - nelle preces delle ore canoniche. La monografia, preparata sopratutto con l'uso del metodo storico-genetico, ha dimostrato la presenza nelle ore canoniche la componente delle preces nell'arco dei secoli, a partire dalle prime testimonianze che realizzano la missione affidata dal Paolo Apostolo in 1 Tm 2, 1-4 fino alla forma delle preces attualmente in vigore contenute inLiturgia horarum.

2. Nel 2000 cardinale Joseph Ratzinger ha pubblicato il libro intitolato Lo spirito della liturgia, i cui contenuti riguardano tra l'altro l'altare, la croce su di esso e l'orientamento delle preghiere. I contenuti presentati dal cardinale nella pubblicazione e la sua polemica con il prof. Pierre-Marie Gy su "La Maison Dieu” hanno suscitato un'ampia discussione tra i teologi, e sopratutto liturgisti. È apparsa la pubblicazione Orientation in liturgical prayer di Uwe Michael Lang, e inoltre lo stesso Benedetto XVI, osservando i dibattiti e le recensioni relative ad uno dei capitoli di Lo spirito della liturgia, intitolato L'altare e l'orientamento della preghiera nella liturgia, preparando il volume 11 della sua Opera omnia dal titolo Teologia della liturgia, aveva perfino l'intenzione di cancellare questo capitolo. Elaborando l'argomento riguardante l'orientamento della preghiera liturgica Joseph Ratzinger si è servito delle ricerche di Erik Peterson. Vale la pena di ricordare qui che il frutto delle ricerche di Erik Peterson è diventato tema del Convegno Internazionle dedicato a Erik Peterson svoltosi nell'ottobre del 2012 a Roma. Le relazioni presentate sono state pubblicate dalla Pontificia Academia Theologica. Il tema dell'orientamento delle preghiere è stato presentato al convegno da Gerard Rouwhorst. Conoscendo tutti questi componenti la Cattedra di Teologia della Liturgia ha presentato la monografia intitolata Ottarz, krzyż i kierunek zanoszonych modlitw. 
